\title{
Teaching in English across the Curriculum: A Lived Experiences of the Novice Teachers in A Selected Rural FET Schools in South Africa
}

\author{
Dumisani W. Mncube ${ }^{1}$, Rachel Gugu Mkhasibe ${ }^{2} \&$ Oluwatoyin Ayodele Ajani ${ }^{1}$ \\ ${ }^{1}$ Social Sciences Education Department, University of Zululand, South Africa \\ ${ }^{2}$ Education Professional Practice, University of Zululand, South Africa \\ Correspondence: Oluwatoyin Ayodele Ajani, Social Sciences Education Department, University of Zululand, South \\ Africa. E-mail: oaajani@gmail.com
}

Received: April 28, 2021

Accepted: June 10, 2021

Online Published: June 11, 2021

doi:10.5430/ijhe.v10n6p72

URL: https://doi.org/10.5430/ijhe.v10n6p72

\begin{abstract}
Novice teachers' use of English as the medium of instruction in curriculum delivery across all subjects in rural South African schools is the focus of this study. The duration of their entry into the profession as Post Graduate Certificate in Education holders is short and does not capacitate them enough, thus, making them weak and inexperienced, with a high degree of professionalism, especially at the commencement of their careers. This study investigates the lived experiences of selected novice rural teachers on the tasks of teaching in English across all subjects in the rural schools. Fifteen participants from 15 high schools were purposively selected from 15 different rural high schools from King Cetshwayo District, KwaZulu-Natal province in South Africa. The participants were engaged in a focus group discussion as well as classroom observations of these teachers for data collection. Data analysis for this qualitative study was thematically analysed to generate themes for the presentation and discussion of findings. Theories of the Skills Acquisition Theory (SAT) and the Second Language (L2) Comprehensible Input through Teacher Talk Theory (CITTT) were adopted as theoretical frameworks to underpin the phenomenon. Various novice teachers find it difficult to teach across all subjects, using English as the medium of instruction in many rural schools in South Africa. Findings indicated that the educational backgrounds of learners hinder teachers' use of English to teach them meaningfully. As observed during various classroom observations, teachers also found it convenient to use indigenous languages to deliver lesson content or communicate to these learners in the classrooms during lessons. Findings also revealed that some teachers struggled to express themselves in English due to their educational backgrounds as well. The study, therefore, recommends that teachers during their pre-service education should be well-groomed in English and this should be promoted during their teaching practice in both rural and urban. Various teacher education institutions should be encouraged to deliver curriculum contents/modules to the pre-service teachers in English across all modules.
\end{abstract}

Keywords: pre-service, novice, rural schools, curriculum delivery, English, indigenous language, teacher education

\section{Introduction}

In many countries, teaching and learning across all subjects or classes in English (as a second language) is becoming more prevalent as a way to improve learners' comprehension and increase their exposure to their global peers (Nel, 2010; Wong, Indiatsi, \& Wong, 2016). Learners whose first language is not English would need extensive training to be accommodated in the use of English as a medium of instruction. Also, inexperienced teachers are affected by this situation because, during their pre-service training, most of them were given very limited knowledge and skills for coping with the reality of teaching across the curriculum in English in rural areas. Furthermore, school districts also struggle to offer sufficient resources to new teachers teaching in rural areas, making it difficult for them to adjust to their new professional environments (Alhamad, 2018). As a result, when they teach the curriculum, using English in rural schools, they struggle to deliver learning to their learners. As a result, according to Bunch (2013), developing pedagogical language awareness through the curriculum is critical in preparing inexperienced teachers to work with learners to raise their language and literacy standards.

According to Holguin and Morales (2016), most new teachers in Columbia are hesitant to teach in rural areas because they know they would not be able to adapt to the unique characteristics of rural education. They point out that these peculiarities are due to a variety of factors, including poverty, which is more prevalent in rural areas due to 
their isolation, and the fact that English is rarely spoken in their everyday lives. Furthermore, policy formulation has mostly centred on metropolitan areas (Holguin \& Morales, 2016). Similarly, the results of Early and Norton's (2014) research in Uganda show the challenges that material teachers face while using English as a medium of instruction in rural African classrooms. They quote Uganda's Minister of Education and Sports as saying that while all subjects in the school curriculum are supposed to be taught well, language education is especially important because it is the foundation for the teaching of all other subjects. He emphasized that learners who do not have a strong command of English as a medium of instruction would struggle in any subject.

\section{Literature Review}

With 11 official languages, South Africa is recognised for being multilingual. All other languages, however, are subordinate to English. According to Dlanga (2011), all other languages in South Africa have been colonized by English. As a result, almost all material subjects are taught in English in most, if not all, public schools. This happens whether or not the learners are native speakers of the language. With rural learners, the problem becomes much worse. Because of the illiteracy and low or non-educational backgrounds of their parents, lack of exposure, and other factors, the majority of them are not exposed to the English language. As a result, teaching and learning processes are affected. In comparison to their rural counterparts, most urban learners benefit from daily exposure to English. Learners who speak English have an advantage because their teachers and the language of instruction are all in English. This means they don't have to try to understand what's being learned because they're already fluent in English, and they don't have any difficulties passing on information to their learners.

The evidence from extant literature suggests that there is a clear link between the amount of English exposure and proficiency in learning the language (Dixon \& Dixon, 2012; Bedore, Pena, Griffin \& Hixon, 2016). While some may argue that success in learning the language is dependent on the qualifications and efficacy of teachers who teach in English across the curriculum, urban learners are more proficient in the language than rural learners. The explanation for this is that learners' relative language proficiency is in certain ways a feature of how much of those languages they are exposed to (Santau, Maerten-Rivera, \& Huggins, 2011). As a result, urban learners have an advantage over their rural peers when it comes to learning English and being fluent bilinguals. The majority of the teachers who work with these learners come from the same background. It's even worse for inexperienced teachers in rural areas who are in charge of Further Education and Training (FET).

Both inexperienced teachers and learners in rural schools, according to Probyn (2010), fail to express themselves openly through the medium of instruction, which is English. She claims that their inability to openly communicate in English has negative implications for teaching and learning. That is why, according to Nel (2010), most teachers are to blame for poor language feedback because of their limited English proficiency. Thus, the purpose of this study is to investigate the experiences of FET inexperienced teachers who are teaching across the curriculum in rural schools in one of South Africa's districts. Masitoh (2015) found that schools in Indonesia that use English as the medium of instruction for all subjects seem to be popular. This success, however, comes at a cost. In addition, Campbell (2014) points out that in Kenya, all subjects in the curriculum are taught in English, regardless of the socioeconomic status of the learners. This means that in Indonesia, the majority of people can afford schooling, while in Kenya, the majority of people live in rural areas and cannot afford it.

Learners who are studying English as a second language require three to five years to become fluent and ready to be taught in English through the curriculum, according to Zamel and Spack (2006). Mashayi (2011) confirms this ground-breaking discovery, stating that educational policies regarding the use of the English language are simple, but they are not universally applied in rural areas as they are in urban areas. The inference is that a mismatch exists between a teacher's home language (HL) and the learners' HL (Zamel \& Spack, 2006). Mathole (2016: 62) emphasises that "the recently published African languages school policy, known as the Incremental Introduction of African Languages (IIAL) policy". The Department of Basic Education (DBE 2013: 6) states three main aims of multilingual education:

- "To improve proficiency in and utilisation of African languages at the home language level, so that learners can use their home language proficiently.

- To increase access to languages for all learners, beyond English and Afrikaans, by requiring all non-African home language speakers to learn an African language.

- To promote social cohesion and economic empowerment and expand opportunities for the development of African languages as a significant way of preserving heritage and cultures". 
With a close examination of the existing African languages (IIAL) school policy, one will observe that the policy is well prepared to address various challenges that the FET novice teachers are facing in an attempt to teach in English across the subject curriculum in the rural schools. However, the policy lacks effective implementation and it has been like that for a very long time (Nkambule \& Mukeredzi, 2017; Seabi, 2020). Teaching across the curriculum with English as the medium of instruction has always been a serious challenge to rural learners in most rural parts of South Africa, the learners are usually comfortable with their indigenous languages (Evans \& Nthulana, 2018). In another study conducted in Rwanda on the impact of using English to teach across the curriculum, Sibomana (2020) posits that learners in rural high schools learn meaningfully with English as a medium of instruction, but could understand better with their indigenous languages. Seemingly, Quansah, Sakyi-Hagan, Essiam (2019) in their longitudinal study conducted in Ghana, teachers revealed that though learners are taught in English as the lingua franca for the country, the learners can still understand better in their local languages.

\section{Theoretical Framework}

Two critical theories have been adopted to underpin the study, thus providing in-depth understanding and strength to the phenomenon. The theories are the Skills Acquisition Theory (SAT) and the Second Language (L2) Comprehensible Input through Teacher Talk Theory (CITTT). "The SAT is the learning of a wide variety of skills which shows a remarkable similarity in development from the initial representation of knowledge through initial changes in behaviour to eventual fluent, spontaneous, largely effortless, and highly skilled behaviour" (Dekeyser, 2007:76). Mystkowska-Wiertelak and Pawlak (2012) explain that this theory is not only concerned with the development of a language, but it is also the theory of learning ranging from cognitive to psychomotor skills. Hence Dekeyser (2007) emphasises that learning in the SAT entails a progression from an attentive to an automatic mode. Therefore, this theory is deemed relevant to this study because both teachers in training and learners are expected to develop in their acquisition of a language, and eventually be able to understand all subjects taught in English.

According to Nel (2010), the L2 CITTT, which was created by Krashen, emphasizes the importance of teachers speaking at a learner's level of comprehension so that learners can understand the lesson or whatever the instructor is conveying to them. According to Nel (2010), the L2 CITTT, which was created by Krashen, emphasizes the importance of teachers speaking at a learner's level of comprehension so that learners can understand the lesson or whatever the instructor is conveying to them. When a person is taught in his or her native language, for example, he or she does not have to struggle to comprehend the language before comprehending the materials (contents).

Similarly, after one has mastered the ability to understand the second language, one does not experience anxiety when being instructed in that language. To put it another way, it becomes easier to understand the language. 'We acquire by understanding the language that contains structure a bit beyond our current level of competence $(i+1)$. This is done with the help of context or extra-linguistic information (Krashen, 1987, p. 21). For language acquisition to take place, "Krashen posits that the teacher uses 'comprehensible input' to facilitate language acquisition. He also refers to 'comprehended' input (Krashen, 1987, p. 33). And if the pupil is at a level that we shall call ' $i$ ', then the aim is for the teacher to raise the level of his/her use of the language to ensure that the pupil is receiving input a bit above ' $i$ ' and hence pushing up acquisition to the next level ' +1 '. This, then, is where the term ' $i+1$ ' stems from: ' $\ldots$ an acquirer can "move" from a stage $i$ (where $i$ is the acquirer's level of competence) to a stage $i+1$ (where $i+1$ is the stage immediately following $\mathrm{i}$ along with some natural order) by understanding language containing $\mathrm{i}+1$ " (Payne, 2011:419).

\section{Research Methodology}

This qualitative research design adopted an interpretive approach to explore lived experiences of the purposively selected participants. "Purposive sampling refers to a series of strategic choices about with whom, where and how a researcher conducts his or her research and the researcher's sample must be tied to the objective of the study" (Palys 2008:697). A total number of 15 novice teachers were purposively selected from 15 FET schools. These participants were novice teachers, teaching various subjects in English across the curriculum. Their teaching experiences were less than five years in the profession, teaching in various rural schools from the King Cetshwayo District, Kwazulu-Natal province of South Africa. The participants were engaged in a focus group interview and were also observed in classroom teaching. Observation and focus group discussion served as instruments for data collection from FET novice teachers. According to Nieuwenhuis (2007:90), "the focus group interview strategy is based on the assumption that group interaction will be productive in widening the range of responses, and activating forgotten details of experiences".

Data from the semi-structured focus group interview was audio recorded with participants' permission, transcribed and coded to generate themes for discussion (Braun \& Clarke, 2006). While observation tool was used for classroom 
observations to capture information correctly. Thematic analysis was used to analyse the qualitative data, following the scientific procedure of Braun and Clarke (2006). The themes were interpretively presented as findings of the study (Grbich, 2007; Javadi \& Zarea, 2016). As part of the ethical procedures, all necessary approvals were obtained before the commencement of the study. Participation was made voluntary, with the participants informed of their willingness/withdrawal at any stage of the study. Informed consents were signed by the participants with an assurance that their information would be kept confidential, and their excerpts presented with pseudonyms in the results.

\section{Results}

Findings from the participants have been presented with pseudonyms (P1, P2, P3...P14, P15) for excerpts to protect the participants' identities. The views indicated their lived experiences using English as the medium of instruction to teach subjects in rural high schools.

\section{Theme 1: Job descriptions for novice teachers}

Entry into the teaching profession entails a well-laid job description for the new teachers who are practically novice in the job. The participants' responses and the observed actions in the classroom indicated that novice teachers have primary responsibilities of facilitating learning amongst others. One of the participants had this to say:

I know as a new teacher in this profession, my main responsibility is to teach my learners to understand. And I know, the learners must understand English. So, we are to teach these learners across the curriculum in English (P5)

Another participant P12 agreed that teaching in English is expected of teachers in South Africa, regardless of their location but rural learners are disadvantaged to understand learning contents in English.

We are new in this profession, and as novice teachers, as we are, we would have loved to teach across curriculum in English as expected but we end up teaching these learners using indigenous languages that have primarily been their language backgrounds from their basic schools. Their educational backgrounds have hindered them from learning in English to understand.

Various observations of the participants' classroom teaching showed that learners could not understand lessons in some selected subjects like Mathematics, Economics, Tourism and Physical Science meaningfully. The participants indicated that they needed to code-switch in local languages for these learners to attain the learning objectives.

I teach Physical Science and I struggle with my learners' inability to understand whenever I teach in English. They only understand better when I code-switch in the Zulu language. I won't blame them because their educational backgrounds have always been in the Zulu language as the means of instruction (P4).

A similar opinion was shared by another participant P11:

I knew from day 1 that learners in FET are to be taught in English across the curriculum, based on the language policy for schools in South Africa. However, it is not a reality for us that are teaching in rural schools. Most of our learners do not understand your lessons, if you teach in English, they will end up looking at you or disturbing your class because they are not carried along. So, if you want them to learn, you teach them in the local language they understand (P11).

The researchers observed that when teachers used indigenous language to teach, the learners became attentive and interested in the lessons. Some teachers who code switched in classes expressed their stresses in doing that.

Eish! It's really stressful, I teach for some minutes in English, wanting to fulfil the expected responsibility of teaching in English in high schools, but I have to explain the same again in Zulu for my learners to understand. So, switching from English to Zulu is really a burden, as you spend more time on this. And at the end, you may not be able to finish the lesson contents at times (P8).

A similar expression was shared by another novice teacher:

We are many that are facing this problem. It is not only the novice teachers, even some senior teachers I have observed, they code-switch between English and Zulu languages to teach the learners. But some of us can't code-switch timely and effectively, so we end up using indigenous languages only to teach (P10).

\section{Theme 2: Novice teachers' lack of comprehension skills}

When inexperienced teachers started to focus broadly on their abilities, the position of a teacher became evident in the curriculum. Teaching through the curriculum means that teachers have acquired the comprehension skills 
necessary to teach. These valuable skills were described by the participants as their most fundamental obstacle to applying the language of teaching and learning in this regard (LoTL). Participants agreed that teaching in English across the curriculum (EAC) is a myth rather than a fact. The fact that the majority of these teachers have trouble understanding English means that their approach toward the language is problematic:

Our PGCE training was just for one year, with teaching practice of few weeks. The experiences at teaching practice for those of us who had it in urban schools exposed us to crowded classes as a challenge but we were able to teach in English, for those of us who are conversant in English. However, our entry into the profession at rural schools created challenges in making our rural learners understand our teaching (P7).

The truth is that some of us lack the necessary skills of teaching in English across the curriculum. We can only teach to understand with indigenous languages (P13).

Learners' backgrounds do not prepare with comprehension skills, and so, they cannot understand even when teachers use English to teach them.

At the FET phase, we cannot be teaching learners basic comprehension skills they supposed to have learnt at previous phases of their educational backgrounds. As much as we use simple vocabularies to teach, they can't still understand. (P9).

\section{Theme 3: Inadequate learning teaching support materials for lesson delivery}

Learning teaching support materials (LTSM) are critical to effective teaching and learning activities in the school system. These materials assist learners in quick comprehension and reduce teachers' stress, hence, the lack of these resources in most rural schools do not enhance teachers' creativity. One of the participants had this:

Rural schools are under-resourced in most parts of South Africa. Without the necessary resources, there is little you can do as teachers. Most of the learners are from poor homes, and cannot afford some learning materials to assist them. It becomes difficult for you to help in such situations (P9).

Another participant concurred that LTSMs are capable of enhancing learners' understanding even with the use of English.

If we have enough resources in schools, learning can be made easy with those materials. Learners are quick to learn with materials that make learning concrete to them, even when they have little knowledge of English (P14).

Participant P9 opined that:

"Textbooks are important to learners, teachers cannot be teaching in the abstract if learners must understand. Availability of necessary books and other materials can assist novice teachers' classroom practices. As novice teachers whose learners lack the necessary textbooks and stationery materials, you struggle to teach".

P12 declared that using adequate LTSMs will assist in teaching learners with English as a second language to promote the language policy of using English as a medium of instruction.

Teaching rural learners in English across the curriculum is a challenging task really if we must follow the language policy. But with adequate resources like LTSMs, we can manage to be teaching using English as a medium of instruction and as a second/additional language with the Zulu language. This is the only way to code switch efficiently (P12).

\section{Theme 4: Novice teachers' need for language acquisition}

The need for novice teachers to acquire appropriate language skills is crucial to teaching and learning. The participants affirmed that language acquisition is important in English as a medium of instruction to both teachers and learners. One participant had this to say:

In any subject you teach as a teacher, you need good mastery of English, this enhances the use of the language across the curriculum. The learners also need to possess or acquire the necessary language skills to learn various subjects in English (P3).

Observations from the classrooms revealed that acquisition of language skills is necessary for understanding and comprehension of learning contents. Participant P8 expressed: 
Language is key to teaching. Delivering learning contents require teachers' possession of language skills to make learners understand, while the learners also need language skills to comprehend. When the language skills of both teachers and learners correspond to each other, learning objectives are attained (P8).

Teachers' usage of language skills with learners' ability to use language literacy enable lessons to be understood by the learners. The language skills promote the presentation of learning in logical manners with learners' ability to comprehend learning in English across the curriculum, through communication skills.

It is difficult to find learners who possess the required language skills that can make them navigate their comprehension in teaching across the curriculum with English (P6).

Language skills assist learners to express their knowledge and understanding in academic writing and reading, using the appropriate literacy in English (P14).

Learners in rural schools do not possess require literacy in English that can make them understand everyday academic writing as demanded by English as a medium of instruction (P10).

\section{Theme 5: Teaching and learning approaches}

Findings reveal that various approaches are available for teaching and learning while using English across the curriculum. Participants mentioned mentoring and support to novice teachers by the experienced teachers, subject advisors, heads of departments, as well as diverse in-service workshops to improve teaching and learning. Participant P9 mentioned:

There are various approaches to teaching learners across the curriculum. As novice teachers, we don't know many, but as we are being mentored and supported by senior experienced teachers, we learn better (P9).

Another participant had this to say:

As we grow in the profession, we learn many new things different from what we started the job with. It is true that as novice teachers, we struggle a lot to achieve learning in our learning, using English as the medium of instruction is quite stressful and challenges to us (P4).

While participant P13 affirmed that the use of English to teach across the curriculum cannot be productive as using indigenous languages of South Africa to teach learners in various rural schools:

As novice teachers, we have discovered that indigenous languages are better than using English as the medium of instruction to teach in a rural school. Our learners' backgrounds do not enhance their learning in English at all! (P1).

Participants affirmed that the environment of the schools determines the use of English as the medium of instructions.

I think other novice teachers who teaching urban schools are better off than those of us, who are teaching in the rural. Learners in urban schools are better in English, and they can understand teaching across the curriculum in English. The learners in urban schools are exposed to multicultural backgrounds (P6).

Most urban schools are using English as their home language which differs from rural schools that have it as a second language. Some rural schools do not offer English at all, so it will be challenging to teach in English across the curriculum (P13).

\section{Theme 6: Supporting novice teachers through mentoring}

Findings revealed the quest or the expectations of novice teachers to be supported by experienced teachers. The participants clamoured for adequate mentoring by the experienced teachers, heads of departments, deputy principals and principals.

We are new to the profession, so it won't be a bad idea if new teachers are assigned to senior and experienced teachers to mentor them to attain professionalism (P4).

I think it is normal for novice teachers to be supported by some of the senior and experienced heads of departments or other teachers, who can guide the new teachers to understand the rural context of teaching and learning (P15).

The environment for rural schools is different from that of urban schools, the teachers in the rural schools need to under their rural learners, to design or adapt teaching approaches that can suit the rural teaching 
and learning. New teachers can only understand the environment of rural schools if they are mentored or supported by senior teachers (P11).

Teaching across the curriculum in some subjects is not possible with indigenous languages, especially some subjects with concepts or topics you can teach in local languages. Subject such as Physical Science has some concepts I can explain in Zulu to my learners, I can only teach these concepts in English. Though, learners find it difficult to under the concepts in English, they prefer to be taught in Zulu (P3).

Support from experienced teachers provides a quick guide to novice teachers. This mentoring approach reduces their stress and learns quickly to adjust to the new profession (P7).

The responsibilities of the senior and experienced teachers in mentoring novice teachers help in capacity building for the new teachers. Mentoring enables the new teachers to be settled within the profession as he/she continues this new profession. This regard appears to be the main glue that can capacitate novice teachers.

\section{Discussion}

According to the findings from extant literature (Mashayi, 2011; Seabi, 2020), inexperienced FET teachers are aware of their roles and responsibilities, which include teaching their subjects in English across the curriculum. They, on the other hand, find this task intimidating and difficult. They cite many points of contention that irritate them, as well as how they believe it stymies progress during implementation, raising concerns about their subject knowledge. In this research, for example, the majority of FET novice teachers teach black African learners who come from traditional, poor family backgrounds and have had little exposure to English. At school, Nel (2010) posits that rural learners converse and socialize in their mother tongue regularly. The FET novice teachers are confronted with challenges that hinder them from teaching in English across the curriculum, as they either teach in indigenous languages or code-switching from indigenous languages to English for their learners to understand their lessons (Evans \& Nthulana, 2018).

According to Early and Norton (2014), these considerations add to the difficulties of teaching and learning; indeed, the majority of participants believe that learning to converse in English is challenging. In theory, most of the participants understood their roles, but implementing this approach had proved more complex (Ajani, 2020). That is why all the participants revealed that teaching their class in English proved fruitless as most learners kept on asking for the repeat of the lesson. The role of an educator is to empower learners with knowledge using language as a medium of instruction. The preferred language of teaching and learning across the curriculum in English, and it takes time to develop this language in rural schools (Quansah, Sakyi-Hagan \& Essiam, 2019).

The majority of participants expressed their dissatisfaction with the strong reliance on English as a LoTL (Mupa \& Chinooneka, 2015; Mathole, 2015). Their sentiments, for example, appeared to undermine the fundamental point that only the English language can transmit information. This point was based on inconsistencies in the curriculum design that require all subjects to be taught and evaluated in the LoTL, which is English. This point is more convincing in the sciences, where most subjects must be taught in English because the vernacular is not mature enough to accommodate adequate learning (Sibomana, 2020). Despite their understanding of their roles, the majority of FET inexperienced teachers do not accept that most lessons should be taught in English, and senior teachers prefer an alternative solution such as code-switching (Early \& Norton, 2014) as a teaching and learning technique.

FET inexperienced teachers are alarmed by code-switching, which was used by seasoned teachers while teaching subjects that were meant to be taught in English. Evans and Nthulana (2018) posit that when it comes to enforcing the strategy of teaching in English through the curriculum, most FET inexperienced teachers are likely to face difficulties. Learners frequently express concern to HoDs about their difficulties interpreting lessons taught when English is used as the LoTL, which adds to the strain. Even the most experienced teachers, according to Mathole (2016), resort to code-switching from English to the learners' mother tongue to bridge the gap in understanding what is being taught during teaching and learning. In certain cases, most HoDs give in to student pressure on new teachers to consider code-switching. However, the unfortunate fact is that both FET novices

The participants recognized the importance of effective information comprehension during the teaching of all subjects across the curriculum. The lack of this crucial competence jeopardizes inexperienced teachers' ability to deliver successful lessons (Evans \& Nthulana, 2018; Quansah, Sakyi-Hagan \& Essiam, 2019). Jordaan, Welman, and Stephen (2004) make the case that weak comprehension of any subject matter hinders second-language speakers, a claim that is borne out when inexperienced teachers begin asking serious questions to test learners' level of understanding before the lesson is facilitated. Findings from the study as well as extant literature affirm that the FET novice teachers in most rural schools lack sufficient reading materials to help novice teachers plan lessons for the 
twenty-first century. Most participants agreed that a teacher who has had little exposure to reading content such as books while planning a lesson influences learners to do less reading and writing (Mashayi, 2011; Mathole, 2015; Evans \& Nthulana, 2018; Seabi, 2020). As a result of the school environment, participants are less likely to continue teaching in English, which is contrary to the profession's core values. According to Ajani (2019), the training they obtained at their institution of higher learning trained them to improvise, but their limited access to reading material thwarts their efforts.

Since these rural schools have been completely neglected in terms of funding, inexperienced teachers have little choices to pursue throughout the teaching and learning process. As a result, improving teaching in certain schools is extremely difficult. This viewpoint is in line with Mupa and Chinooneka's (2015) statement that the availability of textbooks and other LTSMs appears to be the most consistent factor in predicting teacher effectiveness in English teaching across the curriculum. Studies in various countries have found a connection between exposing learners to textbooks and their English language proficiency, which in turn improves educational achievement (Chingos \& West, 2012; Fernandez-Guerra, 2014 \& Bordal, 2016). According to the findings, participants' inability to stimulate discursive activities is hampered by their lack of access to reading content, which reduces their chances of being exposed to a critical study of written text and problem-solving strategies. Findings recognize that most teachers in rural areas work in a demanding and under-resourced environment to achieve miraculous results that meet the community's needs. According to the participants, adjusting to an atmosphere that differs significantly from what they were promised during their preparation takes time. Due to opposition from learners and the local community, Maddock and Marouun (2018) advise inexperienced teachers to adapt quickly to the change in language and embrace the language of teaching and learning encountered in classrooms, which is a new standard for them.

Some of the FET novice teachers are informed that teaching in English across the curriculum is challenging to the majority of teachers in South African rural schools (Sibomana, 2020). The plan, however, was insufficient for the poor rural community in which these schools are located. For most new teachers, incorporating the English language into the teaching of material subjects is a pain in the neck. They'll have to deal with this tactic for the rest of their careers as teachers. This ongoing difficulty in their teaching is in line with the Department of Basic Education's policy paper. "For language acquisition to take place, the teacher needs to use comprehensible input to facilitate language acquisition. He also refers to 'comprehended' input (Krashen, 1987, p. 33). Govender (2018) asserts that encouraging inexperienced teachers to teach material subjects in English allows them to relax or ignore policy imperatives. In essence, participants accept that the educational climate is fertile ground for the future use of indigenous knowledge to compensate for a lack of command and use of the English language. One can only assume that the majority of these participants use their vernacular as a bulwark against opposition from both their colleagues and their learners.

The consensus among participants was that language learning is not a decontextualized ability that can be mastered once and for all by studying only English subjects. It is rather the product of continuous language and academic literacy acquisition (Zamel \& Spack, 2006). Given the wide range of literacies they teach, the participants seem to share the impression that teaching their subjects in English is a deliberate process that encourages learners to lack an in-depth understanding of the subject based on the language of instruction, which is English. According to Azano, Downey, and Brenner (2019), this philosophy emphasizes the idea that learners can learn any language that their teachers can teach them.

This research also discovered that language learning by writing is crucial in the teaching process. The majority of participants stated that incorporating written action into their subject matter had a positive effect. As this is pursued, however, the dialogue between teacher and learner is characterized by a high degree of mistrust and fear. This fear is sparked by learners' poor comprehension and low self-esteem, which is noticeable during teaching and learning, implying that English is treated as a second or third language by the majority of learners. The growing hostility of learners in rural schools against the LoTL, which is used in all of their subjects, has been acknowledged by the participants. According to Probyn (2010), most learners tend to be taught in their mother tongue or an indigenous language to compensate for their lack of comprehension skills in a foreign language.

On the subject of reading and writing, the participants affirmed that when learners are engaged in academic tasks, they struggle to compose short and logical sentences. This deficiency was due to learners' inability to follow language technique as well as the breakdown needed when reconstructing an ambiguous sentence to explain its context. The opinions expressed in this study back up Sosibo's (2015) claim that a person who communicates logically in speech often tends to write logically. The novice teachers say, for example, that to improve professional skills, they should teach according to policy and plan lessons with experienced teachers to benefit from their 
innovations. However, it is entirely dependent on the willingness and skills of these seasoned teachers (Seabi, Montle \& Mogoboya, 2020). Experienced teachers must accommodate inexperienced teachers in their preparation phase, according to novice teachers. Mentoring, according to Mafunganyika and Nkambule (2018), entails a variety of practices, including updating teaching methods for incorporating language into the teaching of content subjects across the curriculum, idea formation, academic writing, reading, and oral presentation.

\section{Recommendations}

Based on the findings from this study, the study recommends some strategies to enhance teaching across the curriculum in English as follows:

- Rural schools should be considered while designing curriculum for every subject to accommodate situational analysis of the rural schools.

- Pre-service teachers should be taught in English across all their modules. English as a medium of instruction should be promoted in teacher education. The pre-service teachers should be made to offer English as a communication language.

- Pre-service teachers on teaching practice should be encouraged to teach using English across the curriculum.

- Appropriate and regular intensive training/workshops should be organized for novice teachers to support them.

- Senior and experienced teachers should be assigned to mentor novice teachers. The mentors should be monitor to ensure mentoring activities that can improve novice teachers' classroom practices.

- Contextualised professional development should be organized for novice teachers to integrate them into the rural school environment.

- Learning teaching support materials should be adequately provided to all rural schools. Learners must be well catered for.

\section{References}

Ajani, O. A. (2019). Understanding teachers as adult learners in professional development activities for enhanced classroom practices. African Journal of Development Studies, 9(2), 195. https://doi.org/10.31920/2075-6534/2019/9n2a10

Ajani, O. A. (2020). Teachers' professional development in South African high schools: how well does it suit their professional needs? African Journal of Development Studies (formerly AFFRIKA Journal of Politics, Economics and Society), 10(3), 59-79. https://doi.org/10.31920/2634-3649/2020/10n3a4

Alhamad, R. (2018). Challenges and induction needs of novice English as a foreign language teacher in Saudi Arabia. International Journal of Education and Literacy Studies, 6(1), 50-63. https://doi.org/10.7575/aiac.ijels.v.6n.1p.50

Azano, A. P., Downey, J., \& Brenner, D. (2019). Preparing pre-service teachers for rural schools. In Oxford Research Encyclopaedia of Education. https://doi.org/10.1093/acrefore/9780190264093.013.274

Bedore, L. M., Pena, E. D., Griffin, Z. M., \& Hixon, J. G. (2016). Effects of the age of English exposure, current input/output, and grade on bilingual language performance. Journal of Child Language, 43(3), 687-706. https://doi.org/10.1017/S0305000915000811

Bordal, G. (2012). A phonological study of French spoken by multilingual speakers from Bangui, the capital of the Central African Republic. Phonological Variation in French: Illustrations from three continents, 23-43. https://doi.org/10.1075/silv.11.03bor

Braun, V., \& Clarke, V. (2006). Using thematic analysis in psychology. Qualitative Research in Psychology, 3(2), 77-101. https://doi.org/10.1191/1478088706qp063oa

Bunch, G. C. (2013). Pedagogical language knowledge: Preparing mainstream teachers for English learners in the new standards era. Review of Research in Education, 37(1), 298-341. https://doi.org/10.3102/0091732X12461772

Caspersen, J., \& Raaen, F. D. (2010). Novice teachers and how they cope. Teachers and Teaching, 20(2), 189-211. https://doi.org/10.1080/13540602.2013.848570 
Chingos, M. M., \& West, M. R. (2012). Do more effective teachers earn more outside of the classroom? Education Finance and Policy, 7(1), 8-43. https://doi.org/10.1162/EDFP_a_00052

Department of Basic Education (DBE). (2013). The incremental introduction of African languages in South African schools. The draft policy, September 2013. Pretoria: Government Printer.

DeKeyser, R. (2007). Skill acquisition theory. Theories in second language acquisition: An introduction, England: Routledge.

DeKeyser, R., \& Craido, R. (2012). Automatisation, Skills Acquisition, and Practice in Second Language Acquisition. The Encyclopaedia of Applied Linguistics, Oxford, UK: Blackwell Publishing. https://doi.org/10.1002/9781405198431.wbeal0067

Dixon, Q. L., \& Dixon, C. (2012). What we know about second language acquisition: A synthesis from four perspectives. Review of Educational Research, 82(5), 5-60. https://doi.org/10.3102/0034654311433587

Dlanga, K. (2011). 'Blacks, you are lazy'. Retrieved 11 January 2020 from http://www.news24.com/Columnists/Khaya-Dlanga/Blacks-you-are-lazy-20111103

Du Plessis, P., \& Mestry, R. (2019). Teachers for the rural schools-a challenge for South Africa. South African Journal of Education, 39. https://doi.org/10.15700/saje.v39ns1a1774

Early, M., \& Norton, B. (2014). Revisiting English as a medium of instruction in rural African classrooms. Journal of Multilingual and Multicultural Development, 35(7), 674-691. https://doi.org/10.1080/01434632.2014.908890

Evans, R., \& Nthulana, I. (2018). Linguistic challenges faced by rural Tshivenda-speaking teachers when Grade 4 learners transition to English. TD: The Journal for Transdisciplinary Research in Southern Africa, 14(2), 1-9. https://doi.org/10.4102/td.v14i2.545

Fernández-Guerra, A. (2014). The usefulness of translation in foreign language learning: Learners' attitudes. International Journal of English Language \& Translation Studies, 2(1), 153-170.

Govender, S. (2018). South African teachers' perspectives on support received in implementing curriculum changes. South African Journal of Education, 38(1), S1-S12. https://doi.org/10.15700/saje.v38ns2a1484

Grbich, C. (2007). Qualitative data analysis: An introduction, Sage, Thousand Oaks, CA.

Holguín, B. R., \& Morales, J. A. (2016). English language teaching in rural areas: A new challenge for English language teachers in Colombia. Guadernos de Lingüística Hispánica, 27, 209-222. https://doi.org/10.19053/0121053X.4217

Javadi, M., \& Zarea, K. (2016). Understanding thematic analysis and its pitfalls. Journal of Client Care, 1(1), 33-39. https://doi.org/10.15412/J.JCC.02010107

Jordaan, W. J., Welman, J. C., \& Stephen, D. F. (2004). English language proficiency as an indicator of academic performance at a tertiary institution. SA Journal of Human Resource Management, 2(3), $42-53$. https://doi.org/10.4102/sajhrm.v2i3.48

Krashen, S. (1987). Principles and practice in second language acquisition. https://doi.org/10.1111/j.1467-971X.1982.tb00476.x

Maddock, L., \& Maroun, W. (2018). Exploring the present state of South African education: Challenges and recommendations. South African Journal of Higher Education, 32(2), 192-214. https://doi.org/10.20853/32-2-1641

Mafunganyika, A., \& Nkambule, T. (2018). Exploring and understanding rural teachers' conceptions of learning and teaching in schools of Acornhoek district, Mpumalanga Province. The Independent Journal of Teaching and Learning, 13(1), 69-85.

Mashayi, F. N. N. (2011). How South African teachers make sense of language-in-education policies in practice. Doctoral thesis, University of Pretoria.

Masitoh, D. (2015). English Education Department, Faculty of Teacher Training and Education, University of Nusantara Pgri Kediri. Doctoral thesis, Universitas Nusantara PGRI Kediri.

Mathole, Y. (2016). Using content and language integrated learning (CLIL) to address multilingualism in South African schools. European Journal of Language Policy, 8(1), 57-77. https://doi.org/10.3828/ejlp.2016.5 
Mupa, P., \& Chinooneka, T. I. (2015). Factors contributing to ineffective teaching and learning in primary schools: Why are schools in decadence? Journal of Education and Practice, 19, 1735-2222.

Mystkowska-Wiertelak, A., \& Pawlak, M. (2012). Production-oriented and comprehension-based grammar teaching in the foreign language classroom. Heidelburg, NewYork, Springer Science \& Business Media. https://doi.org/10.1007/978-3-642-20856-0

Nel, N. (2010). The impact of teachers' limited English proficiency on English second language learners in South African schools. South African Journal of Education, 30(4), 635-650. https://doi.org/10.15700/saje.v30n4a393

Nkambule, T., \& Mukeredzi, T. G. (2017). Pre-service teachers' professional learning experiences during rural teaching practice in Acornhoek, Mpumalanga Province. South African Journal of Education, 37(3). https://doi.org/10.15700/saje.v37n3a1371

Nieuwenhuis, J. (2007).'Qualitative research designs and data gathering techniques, in K. Maree (ed.) First steps in research, 70-92, Van Schaik Publishers, Pretoria, South Africa.

Palys, T. (2008). Purposive sampling, in L.M. Given (ed.), The SAGE encyclopaedia of qualitative research methods, 1(2), 697-698, Sage, Thousand Oaks, CA.

Payne, M. (2011). Exploring Stephen Krashen's ' $i+1$ ' acquisition model in the classroom. Linguistics and Education, 22(4), 419-429. https://doi.org/10.1016/j.linged.2011.07.002

Probyn, E. (2010). 'Writing shame' in Gregg, J. and Seigworth, G. J. (2010) editors, The Affect Theory Reader, Durham: Duke University Press. https://doi.org/10.1215/9780822393047-003

Quansah, R. E., Sakyi-Hagan, N. A., \& Essiam, C. (2019). Challenges Affecting the Teaching and Learning of Integrated Science in Rural Junior High Schools in Ghana. Science Education International, 30(4), 329-333. https://doi.org/10.33828/sei.v30.i4.10

Santau, A. O., Maerten-Rivera, J. L., \& Huggins, A. C. (2011). Science achievement of English language learners in urban elementary schools: Fourth-grade student achievement results from a professional development intervention. Science Education, 95(5), 771-793. https://doi.org/10.1002/sce.20443

Seabi, P. (2020). Exploring innovative pedagogical methods of teaching English literature in South African secondary schools (Doctoral dissertation, University of Limpopo, South Africa). https://doi.org/10.31920/2634-3622/2020/9n2a6

Sibomana, E. (2020). Transitioning from a local language to English as a medium of instruction: Rwandan teachers' and classroom-based perspectives. International Journal of Bilingual Education and Bilingualism, 1-16. https://doi.org/10.1080/13670050.2020.1749554

Sosibo, Z. (2015). Support strategies for scaffolding learners' acquisition of academic literacy skills: Experiences at a University of Technology. Alternation Journal: Interdisciplinary Journal for the study of the Arts and Humanities in Southern Africa, 22(17), 142-167.

Wong, C. Y., Indiatsi, J., \& Wong, G. K. (2016). ESL teacher candidates' perspectives of strengths and inadequacies of instructing culturally and linguistically diverse learners: Post-clinical experience. Journal of Cultural Diversity, 23(2), 57-64.

Zamel, V., \& Spack, R. (2006). Teaching multilingual learners across the curriculum: Beyond the ESOL classroom and back again. Journal of Basic Writing, 25(2), 126-152. https://doi.org/10.37514/JBW-J.2006.25.2.07

\section{Copyrights}

Copyright for this article is retained by the author(s), with first publication rights granted to the journal.

This is an open-access article distributed under the terms and conditions of the Creative Commons Attribution license (http://creativecommons.org/licenses/by/4.0/). 